\title{
Smoking, information sources, and risk perceptions- New results on Swedish data
}

\author{
Petter Lundborg
}

Published online: 25 April 2007

(C) Springer Science + Business Media, LLC 2007

\begin{abstract}
Using data on Swedish adolescents, this study examines (1) perceptions of the addictiveness and mortality risk of smoking, (2) the effects of these perceptions on smoking behaviour, and (3) the role of various smoking risk information sources. The average respondent believed that 46 out of 100 smokers would die from diseases caused by their smoking. As to addictiveness perceptions, the average respondent believed that 68 out of 100 smokers trying to quit would not succeed. Both a higher perceived addictiveness and a higher perceived mortality risk were negatively related to smoking participation. The results showed substantial variation in the weight that the teenagers attached to the various information sources.
\end{abstract}

Keywords Smoking $\cdot$ Risk perception $\cdot$ Young people $\cdot$ Risky behaviour

JEL Classification $\mathrm{D} 81 \cdot \mathrm{I} 10 \cdot \mathrm{J} 13$

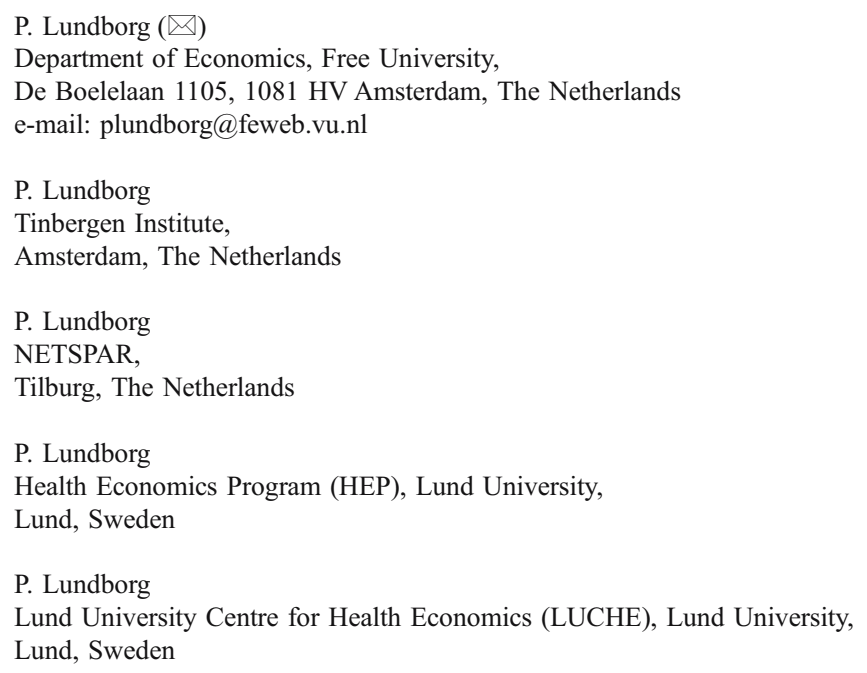


Making the risky decision to smoke not only involves considering the potential adverse health effects but also the addictiveness of cigarettes. The latter is related to both the probability of getting addicted, as an early experimenter with cigarettes, as well as to the cost of changing one's behaviour as a smoker (Orphanides and Zervos 1995). The capability of teenagers to adequately assess and consider the addictiveness and mortality risk of smoking, however, has been commonly questioned (World Bank 1999, ch. 3). In that case, a potential market failure may exist and teenagers may later regret their initial choice to become a smoker. Actually, such regret is commonly stated by smokers. ${ }^{1}$

In this paper, I make two particular contributions to the literature on smoking and smoking-risk perceptions. First, by making use of quantitative estimates of both the perceived addictiveness and mortality risk of smoking, a blank is filled in the literature, which, to date, has mainly focused on the perceived risks of smoking-related morbidity or mortality (e.g. Viscusi 1991, 1998; Liu and Hsieh 1995; Viscusi et al. 2000; Antoñanzas et al. 2000; Viscusi 2002; Lundborg and Lindgren 2004). ${ }^{2}$ The omission of perceptions of addictiveness from these studies has been subject to criticism, since even though smokers may be well-informed about the health risks of smoking, they may still neglect and/or misperceive the addictive potential of smoking and, thus, the associated costs of quitting smoking (Slovic 2000).

Second, I contribute to the understanding of how smoking-risk perceptions are formed by considering the role that various information sources play, in addition to socio-economic and demographic factors. When learning about risks, teenagers may attach different weights to different information sources, such as media, parents, peers, siblings, and teachers. Prior studies on the issue, however, have mainly focused on the influence of factors such as age and gender in the learning process (e.g. Viscusi 1991; Liu and Hsieh 1995; Lundborg and Lindgren 2004) and, to date, little is known about the role of various information sources. ${ }^{3}$ Such an analysis would also provide an interesting case study in the formation of risk perceptions of hazardous products as well as provide results that could inform policy-makers.

In order to address these issues, I use data from 2003 on 9,272 Swedish teenagers aged 15-18. Examining risk perceptions and smoking behaviour among individuals in this age group is particularly relevant, since most smokers initiate smoking during these ages. In Sweden, it is estimated that eight out of ten smokers became continuing

\footnotetext{
${ }^{1}$ It should be noted that expressing regret by no means must imply that the initial smoking decision was irrational. In the model of Orphanides and Zervos (1995), for instance, an individual is initially unaware of his/her addictive potential. Only through experimentation is the individual able to reveal his/her potential, and the probability of experimenting with a substance is larger when the perceived risk of addiction is smaller. Consequently, an individual may choose to gamble, unaware of his/her own addiction potential, and once caught in an addiction, regret his/her choice. This kind of regret can be compared to the ex post regret expressed by a gambler whose gamble has not paid off (Jones 1999).

${ }^{2}$ Qualitative assessments of both the perceived addictiveness and mortality risk of smoking are quite common, though. In Hersch (1998), for instance, respondents were asked whether they believed that smoking was an addiction, a habit, both a habit and an addiction, or neither. Such judgements, however, tell us little about the perceived strength of addiction and make comparisons across individuals difficult.

${ }^{3}$ An exception is Lundborg and Lindgren (2002) where it was found that having received education about alcohol, narcotics, and drugs at school actually lowered risk perceptions regarding alcoholism.
} 
smokers during their teens (SOU 1999, p.137). Moreover, teenage smoking is of great concern to policy-makers in most countries.

My results show quite substantial awareness of smoking mortality risk, the average respondent believing that $46 \%$ of all smokers will eventually die from a smokingrelated disease. Moreover, the average respondent believes that 68 out of 100 smokers trying to quit will fail to do so. Some striking group differences emerge, however. Girls hold lower perceptions of the addictiveness of smoking than boys, but at the same time perceive the mortality risk as greater. As to mortality risk, significant differences across age and smoking status are also obtained.

There was substantial variation in the weight that teenagers attached to the various information sources considered. While information from sources such as teachers at school is positively and significantly related to risk perceptions, several of the most common information sources, such as media and parents, are not significantly related. In the case of perceptions of addictiveness, none of the information sources show any significant correlation with the former, possibly suggesting that the informational content of these sources is low. Several of the information sources show a significant correlation with the smoking probability, after controlling for risk perceptions, suggesting that aspects other than the addictiveness and mortality risk of smoking had been included in the information efforts.

Both higher perceived addictiveness and mortality risk are found to be significantly and negatively related to the probability of smoking. Consequently, even teenage smokers, at least to some extent, seem to consider both the addictiveness of smoking and the mortality risk when deciding whether to smoke or not. Conditional on smoking, however, these perceptions show no statistically significant correlation with the intensity of smoking. This may reflect a lack of understanding as to how different levels of smoking will affect mortality risk and quitting costs.

In the next section, tobacco laws and regulations in Sweden are reviewed. Section 2 then presents the data used for the analysis and Section 3 presents the empirical methodology. In Section 4, the results are presented and the paper ends with a summary and discussion in Section 5.

\section{Tobacco regulation in Sweden}

Whereas mandatory on-product warnings on cigarette packages were introduced in the US in 1965, it was not until 1977 that similar regulations were introduced in Sweden. Each cigarette package now had to include one out of a series of 16 warnings. Typical warnings were: "Smokers are more often sick than non-smokers," "Smokers face an increased risk of vascular diseases and some diseases in the bloodvessels," "Smoking when pregnant may harm your baby," and "Smoking damages the lungs! It starts with coughing and may end with lung-cancer or another lung disease." The warnings were later modified on four occasions during the period 1977-1994. In 1979, warnings such as "Lung cancer causes more deaths than traffic. Most cases of lung cancer are caused by smoking," "What cigarettes are most dangerous? Those with the highest levels of carbon monoxide, tar, and nicotine. Compare the declaration of contents of different brands" appeared. 1982 saw the introduction of warnings such as "9 out of 10 patients with throat cancer are 
smokers." In 1987, the number of different warnings in place was reduced to 13 , since three were not accepted by the government. Some new messages introduced were: "In 1983, 779 persons died in traffic and at least 8,000 died because of smoking," and "Smoking increases the risk of inflammation in the gums. This may lead to periodontitis." The overwhelming majority of warning texts during the period 1977-1994 concerned smoking-related morbidity and mortality to the smoker him/ herself. To a lesser extent the texts concerned the risks of smoking during pregnancy and passive smoking. Interestingly, none of the texts during the period concerned the addictiveness of smoking.

In 1994 a new tobacco law, the Swedish Tobacco Act, was introduced. The act contained provisions for restrictions on smoking in certain indoor premises and indoor areas, smoke-free work environments, warning texts and contents declarations on the packaging of tobacco products, and restrictions on the marketing of tobacco products. This law replaced and strengthened earlier legislation and new amendments have been added over time.

The Swedish Tobacco Act of 1994 stipulated that two separate warning texts now had to be included on every pack. On one side of the package, the text "Tobacco seriously endangers your health" had to be included. On the other side, the package had to contain one of the following eight warnings: "Smoking causes cancer," "Smoking causes cardiovascular diseases," "Smoking causes life-threatening diseases," "Smoking kills," "Smoking when pregnant harms your baby," "Protect children: don't make them breathe your smoke," "Smoking harms those around you," and "Smoking causes addiction." Thus, the risk of addiction was now included in one of the warning texts. The warnings should cover at least $4 \%$ of the surface of the package and should be easy to read. Moreover, it was now required that all cigarette packages should be provided with a declaration of contents, covering at least $4 \%$ of the side of the package.

In 2001, the warnings were changed again and each package now had to include one of the two messages "Smoking kills" or "Smoking seriously harms you and others around you." The message now had to cover at least $30 \%$ of the surface. In addition, a second warning text, covering $40 \%$ of the surface had to be included, containing one of the following 12 texts: "Smokers die younger," "Smoking clogs the arteries and causes heart attacks and strokes," "Smoking causes fatal lung cancer," "Smoking when pregnant harms your baby," "Protect children: don't make them breathe your smoke," "Smoking is highly addictive. Don't start," "Stopping smoking reduces the risk of fatal heart and lung diseases," "Smoking can cause a slow and painful death," "Smoking may reduce the blood flow and causes impotence," "Smoking causes aging of the skin," "Smoking can damage the sperm and reduces fertility," and "Smoke contains benzene, nitrosamines, formaldehyde and hydrogen cyanide."

Regarding the school environment, the tobacco law of 1994 forbids smoking in all school facilities as well as smoking in the schoolyard, but smoking may be permitted in designated rooms or areas, provided that children and young people do not have access to them. Similar rules apply for other public premises, e. g. those in which cultural or sporting events take place.

Prior to 1997 , no age limit for the buying or selling of cigarettes was in place and an attempt to introduce it in 1991 was rejected by the parliament. In 1997, however, 自 Springer 
the tobacco law was modified and the selling of tobacco products to anyone below 18 years of age was forbidden. The age limit only concerned selling, not buying. The observance of the law has been limited, however, and many young people are still able to buy cigarettes. In 2003, for instance, $60 \%$ of smokers aged 15-16 stated that they bought the cigarettes themselves, mainly at the local corner shop (CAN 2004). The law of 1997 also required that all sales of tobacco products to consumers shall be conducted in such a way that it is possible to determine the age of the recipient, which also applies to vending machines etc.

The tobacco law further restricted the possibilities to market tobacco products. All marketing in periodical publications and radio or television was forbidden. In all other cases the law stipulated that marketing should exercise especial moderation, meaning that advertising may not be obtrusive or soliciting, or encourage the use of tobacco products. In practice, this meant a ban on outdoor advertising campaigns and direct marketing through mail etc.

In 2002, a number of additional restrictions were adopted. Tobacco products were no longer allowed to include any text or name, such as "light," that communicates the message that the product is less harmful than others. Indirect advertising - for example, the sales of clothing and shoes that include a tobacco-product trademarkwas also forbidden. In addition, all restaurants were required to have designated smoke-free areas. The law was further strengthened in 2004, with the decision to ban smoking in all types of restaurants, bars, and cafés starting June 2005. Smoking is still allowed however in special rooms set aside for smoking, where no food or drink is allowed, and in outdoor service areas.

Education about alcohol, narcotics, and tobacco (ANT) is a compulsory subject in Swedish schools. Traditionally, the education has been focused on facts, risks, and medical and social damage created by alcohol, narcotics, and tobacco (Skolverket 2000). In addition, both government bodies and independent organisations have over the years conducted various campaigns aimed at reducing smoking among teenagers. In 2004, for instance, a large quit-smoking campaign was launched by the National Cancer Society, with financial support from, among others, the National Institute of Public Health. The most controversial campaigns have been launched by the independent organisation A Non-Smoking-Generation. In 1994 they launched a large advertising campaign against Philip Morris, with pictures of gravestones accompanied by the text "Welcome to Marlboro Country." Other campaigns by the organisation that yielded attention were the "Raped by a Prince" campaign, alluding to the effect of smoking on the bodies of young women, and a campaign showing dead bodies and cigarette packs, coupled with the message "Why?" Additional campaigns have been directed at girls and young women. Between 1996 and 2000, for instance, Miss Sweden contestants were involved in non-smoking educational campaigns for young girls in co-operation with popular women's magazines.

\section{Data}

I use data from an alcohol and drug survey, conducted in Swedish schools in 2003. The survey was conducted in the County of Scania in the south of Sweden and was administered by CERUM, a consultative support team for the municipalities of 
Scania, which is funded by the Ministry of Health and the County of Scania. ${ }^{4}$ The questionnaires were handed out to the pupils in the classrooms and were to be filled in anonymously under the supervision of a teacher. Totally, 9,963 individuals aged 12-18 participated in the survey. Out of these 9,963 individuals, 9,272 were aged 15-18. I used the latter age group for the analyses. Besides data on risk perceptions, the survey collected extensive socio-economic and demographic information as well as detailed information on consumption of addictive substances, such as alcohol, tobacco, and illicit drugs.

The questions on smoking behaviour began with a question about the current smoking status of the respondent. Following previous studies, I defined a smoker as someone who reported smoking every or almost every day (Lundborg and Lindgren 2004; Lundborg 2006). Former smokers and individuals reporting that they don't smoke, almost never smoke, only smoke at parties, or only at week-ends were consequently defined as non-smokers. Using this definition, about $13 \%$ of the sample was defined as smokers. Among girls, 16\% were smokers, whereas among boys $10 \%$ smoked.

Smokers were also asked about their smoking intensity. The alternatives given were 1-2, 3-6, 7-10, 11-16, 17-20, and more than 20 cigarettes a day. Consequently, six different smoking categories were defined. The most common category among smokers was smoking 3-6 cigarettes a day (31\%), whereas smoking more than 20 cigarettes a day was the most uncommon (3\%). In the regressions, a categorical variable, taking on values between 1 and 6 was employed.

Turning to risk perceptions, and the perceived smoking mortality risk, I used a format similar to the one used in Viscusi (2002). The question was framed as:

In a group of 100 smokers, how many do you think will die from diseases caused by their smoking?

The responses were then divided by 100 in order to obtain the perceived probability of dying from smoking-related diseases. For a discussion of the question format, see Viscusi (2002). The question used by Viscusi was somewhat different: "Among 100 smokers, how many of them do you think will die from lung cancer, heart disease, throat cancer, and all other illnesses because they smoke?"5 Next, the perceived addictiveness of smoking was assessed. This question was framed as follows:

In a group of 100 smokers who try to quit, how many do you think will succeed?

The format of the question certainly resembles that used by Viscusi (1991) and Lundborg and Lindgren (2004), since it uses a 0-100 scale. To the knowledge of the author, however, the question does not seem to have been used in prior studies. ${ }^{6}$ Its usefulness will, therefore, be assessed by examining its relationship with actual

\footnotetext{
${ }^{4}$ I am grateful to Martin Stafström for providing me with the data set.

${ }^{5}$ Viscusi used minor variations to this question in three separate surveys in the US. See Viscusi 2002, p. 147.

${ }^{6}$ A similar question, let alone with a different denominator, was used in the Annenberg Surveys (Jamieson and Romer 2001).

型 Springer
} 
smoking behaviour. The responses were divided by 100 to obtain the perceived probability of quitting smoking, denoted $P Q$. Next, the perceived addictiveness was calculated as $1-P Q$, indicating the probability of not being able to quit.

In order to assess from which information sources the respondent had received smoking-risk information, a number of alternatives were given. They were: (1) own information search, (2) teachers at school, (3) other adult at school, (4) parents, (5) siblings, (6) pals, (7) other adults, (8) television, (9) newpapers or magazines, (10) radio, (11) other sources. The respondent was asked to mark from which of these sources he/she had received information. The three variables reflecting media sources, i.e. television, newpapers and/or magazines, and radio, were merged into one variable labelled media. Thus, nine information-source variables were used in the regressions.

As additional explanatory variables, gender, grade, whether born in Sweden or not, income, parents' education and whether living with both parents were used. In the sample, individuals were either in grade 9 in compulsory school or grade 2 in upper secondary school. The former students were 15-16 years old, whereas the latter students were 17-18 years old.

The education of the respondent's parents was assessed by asking the respondent to mark the relevant category for his/her mother and father, respectively. A dummy variable was created, indicating whether the respondent's mother/father had a university education. A separate dummy variable was also created for those who answered that they didn't know the education of their father/mother. This strategy was chosen, since dropping missing responses would incur a loss of roughly $20 \%$ of the sample. ${ }^{7}$

Income was assessed by asking the respondent: "How much money are you able to spend each month (monthly pocket money+other income)." The respondent was then asked to mark the relevant category out of $7 .^{8}$

In Table 1, I present the descriptive statistics. In many respects the sample resembles the characteristics of the average Swedish teenager at the same age. A comparison with the results from the nationally representative surveys on alcohol and drug habits of young people in Sweden reveals, however, that the smoking rates are somewhat higher in our sample. Among girls aged 15-16, the smoking rate in our sample is $14.5 \%$, whereas the corresponding rate at the national level is $13 \%$ (CAN 2004). Among boys aged 15-16, the corresponding rates are 9 and $7 \%$, respectively. For the age group 17-18, national smoking rates were assessed in 2004, but not in 2003, allowing only an imperfect comparison with our sample (CAN 2004). Among the girls aged $17-18$ in our sample $19 \%$ were smokers, whereas $17 \%$ were smokers at the national level. For boys at the same age, the corresponding rates were 11 and $10 \%$, respectively.

The fraction of females and the fraction born in Sweden in our sample are similar to the corresponding fraction at the national level (50 vs $49 \%$ and 90.5 vs $90.1 \%$,

\footnotetext{
${ }^{7}$ I also tried regressions dividing the non-university category into two separate categories, indicating elementary school education only and secondary school education. However, with elementary school as the omitted reference category, the indicator for secondary school was never significant.

${ }^{8}$ The categories were: (1) less than SEK 500 per month, (2) SEK 500-799, (3) SEK 800-1,099, (4) SEK 1,100-1,399, (5) SEK 1,400-1,699, (6) SEK 1,700-1,999, (7) SEK 2,000 or more. In 2003, 1 USD corresponded to about SEK 8.
} 
Table 1 Descriptive statistics

\begin{tabular}{|c|c|c|c|c|c|c|}
\hline \multirow[t]{2}{*}{ Variable } & \multicolumn{2}{|c|}{ Full sample } & \multicolumn{2}{|c|}{ Smokers } & \multicolumn{2}{|c|}{ Non-smokers } \\
\hline & mean & $\mathrm{sd}$ & mean & sd & mean & $\mathrm{sd}$ \\
\hline Perceived smoking mortality risk & 0.456 & 0.272 & 0.406 & 0.270 & 0.464 & 0.271 \\
\hline Perceived addictiveness & 0.677 & 0.218 & 0.641 & 0.238 & 0.683 & 0.214 \\
\hline Smoker & 0.131 & 0.337 & 1.000 & 0.000 & 0.000 & 0.000 \\
\hline Female & 0.500 & 0.500 & 0.622 & 0.485 & 0.485 & 0.500 \\
\hline Grade 9 & 0.593 & 0.491 & 0.534 & 0.499 & 0.603 & 0.489 \\
\hline Born in Sweden & 0.905 & 0.293 & 0.869 & 0.337 & 0.910 & 0.286 \\
\hline Living with both parents & 0.699 & 0.459 & 0.509 & 0.500 & 0.728 & 0.445 \\
\hline Mother has university education & 0.305 & 0.461 & 0.239 & 0.426 & 0.316 & 0.465 \\
\hline Don't know mother's education & 0.211 & 0.408 & 0.263 & 0.441 & 0.203 & 0.402 \\
\hline Father has university education & 0.289 & 0.453 & 0.212 & 0.409 & 0.301 & 0.459 \\
\hline Don't know father's education & 0.239 & 0.426 & 0.329 & 0.470 & 0.225 & 0.418 \\
\hline Income category 2 & 0.223 & 0.416 & 0.172 & 0.378 & 0.230 & 0.421 \\
\hline Income category 3 & 0.350 & 0.477 & 0.375 & 0.484 & 0.347 & 0.476 \\
\hline Income category 4 & 0.092 & 0.289 & 0.112 & 0.316 & 0.090 & 0.286 \\
\hline Income category 5 & 0.042 & 0.201 & 0.060 & 0.237 & 0.040 & 0.195 \\
\hline Income category 6 & 0.025 & 0.156 & 0.027 & 0.163 & 0.025 & 0.155 \\
\hline Income category 7 & 0.076 & 0.266 & 0.130 & 0.337 & 0.068 & 0.252 \\
\hline Information searched by the respondent him/herself & 0.099 & 0.299 & 0.109 & 0.311 & 0.097 & 0.297 \\
\hline Information by teacher & 0.668 & 0.471 & 0.642 & 0.480 & 0.672 & 0.470 \\
\hline Information by other adult at school & 0.307 & 0.461 & 0.242 & 0.428 & 0.318 & 0.466 \\
\hline Information by parents & 0.474 & 0.499 & 0.546 & 0.498 & 0.465 & 0.499 \\
\hline Information by siblings & 0.086 & 0.281 & 0.113 & 0.317 & 0.083 & 0.276 \\
\hline Information by friends & 0.152 & 0.359 & 0.224 & 0.417 & 0.141 & 0.348 \\
\hline Information by other adults & 0.185 & 0.388 & 0.218 & 0.413 & 0.180 & 0.384 \\
\hline Information by $\mathrm{TV}$, magazines or radio & 0.625 & 0.484 & 0.650 & 0.477 & 0.623 & 0.485 \\
\hline Information by other sources & 0.057 & 0.231 & 0.064 & 0.244 & 0.056 & 0.230 \\
\hline
\end{tabular}

respectively). For the income, the education of parents, and the fraction living with a single parent there are no comparable rates from adolescent surveys at the national level. It could be noted though that the fraction of divorced adults is roughly the same in the county of Scania as in Sweden as a whole (9.7 vs. 9.2\%). The average income is slightly lower in Scania compared to the average income at the national level (SEK 204,441 vs. SEK 215,971) and the fraction of individuals with a university education is roughly similar (10.7 vs. $10.4 \%)$.

\section{Empirical methodology}

The formation of smoking risk perceptions may be analysed within a Bayesian learning framework, in which the individual receives risk information from a number of different sources (Viscusi 1991). In this framework, the individual's risk perception can be stated as a weighted average of these different types of information sources (for a more detailed exposition, see Viscusi 1991 or Lundborg and Lindgren 2004). Following this tradition, the risk perception equation to be estimated for person $i$ may be written as:

$$
\operatorname{RISK}_{i}=\alpha_{0}+\alpha_{1} X_{1 i}+\alpha_{2} X_{2 i}+u_{i} .
$$


Here $X_{j i}$ is a vector of variables representing each source $j$ of information for individual $i$ ( $j=1$ individual experience, and $j=2$ direct information transfer via information sources), $\alpha_{j}$ is the associated vector of coefficients, and $u_{i}$ is a random term. ${ }^{9}$ Direct information transfer here concerns the various information sources from which the respondent had received smoking risk information. Individual experience of smoking will be affected by a range of factors. Besides smoking, factors such as age, gender, and education of parents may be related to both the exposure to smoking and various information sources. This may, in turn, affect perceptions of addictiveness and mortality risk. Equation 1 was estimated using the ordinary least squares technique (OLS). ${ }^{10}$

There are several arguments both for and against including smoking status as an explanatory variable in the risk perception equation above. First, consider a Bayesian learning model, where own experience regarding the health effects of one's smoking may lead the individual to revise his/her prior risk perceptions (Viscusi 1991). This mechanism, however, appears weak when it comes to younger smokers, since health effects are unlikely to have occurred yet. Consequently, own smoking is unlikely to affect smoking mortality risk perceptions by this mechanism. Perceptions of addictiveness, on the other hand, seem more likely to be affected by own smoking, since the individual may have tried to quit smoking and subsequently revised his/her perception. Another argument for including smoking status would be if smokers indulge in rationalising behaviour, i.e. a psychological mechanism where the individual deliberately ignores or downplays the risks to him/herself, in order to motivate continued smoking. In that case, a negative effect of smoking on risk perceptions would result. However, a similar effect would occur if risk perceptions affect smoking behaviour, i.e. a case of reverse causality. In both cases, smoking will be endogenous in Eq. 1. Endogeneity problems will also be present if there are unobserved variables, such as personality traits, that affect both smoking and risk perceptions.

To check for potential endogeneity of smoking in Eq. 1, instrumental-variables (IV) estimation was conducted. ${ }^{11}$ Appropriate instruments should be (1) correlated

\footnotetext{
${ }^{9}$ Since cross-section data were utilised, prior risk beliefs could not be assessed.

${ }^{10}$ Since respondents are clustered within classes, their error terms may be correlated. Standard errors will be biased unless this correlation is corrected for. Hence, Eq. 1 was estimated using STATA's robust "sandwich" estimator, allowing for clustering within classes.

${ }^{11}$ Heteroscedasticity is likely to be a problem, since micro-level data is used. The conventional IVestimator will then produce inconsistent standard errors, however. This also means that diagnostic tests, for instance, of overidentifying restrictions and endogeneity will be invalid. In order to better deal with heteroscedasticity of unknown form, I therefore used a Generalised Method of Moments (GMM) estimator (Hansen 1982). The IV-GMM estimator, described in Baum et al. (2003), allows for efficient estimation under unknown heteroscedasticity. Since GMM comes with the cost of possibly poor finite sample performance, I first tested for heteroscedasticity, using the Pagan and Hall test, designed for testing for the presence of heteroscedasticity in the context of IV estimation (Pagan and Hall 1983). Other tests are available as well, such as the Breusch-Pagan (1979) and the Godfrey (1978) tests. These tests, however, will only be valid tests for heteroscedasticity in the IV-regression, if heteroscedasticity is only present in that equation and nowhere else in the system (Pagan and Hall 1983). The Pagan and Hall test relaxes this requirement and is therefore employed in our case. If heteroscedasticity was found to be a problem, the instrumental-variables GMM estimator would be applied, otherwise the ordinary OLS IV-regression estimator would be used.
} 
with the potentially endogenous right-hand-side variable and (2) orthogonal to the error process. The former requirement was tested for by first conducting an $F$-test of the joint significance of the instruments, as suggested by Bound et al. (1995). Second, I examined the partial $R^{2}$ from the first-stage regression (Bound et al. 1995). The second requirement, the validity of the overidentifying restrictions, was tested via the $J$ statistic by Hansen (1982). ${ }^{12}$ Once valid instruments were found, I tested the endogeneity of smoking. ${ }^{13}$

Finding appropriate instruments for smoking is a difficult task, since they should affect smoking but not risk perceptions. The first instrument considered was peer smoking. Peer smoking has been found to strongly influence the smoking decision of the individual (e.g. Lundborg 2006). The existence of peer effects has been explained by mechanisms such as pay-off mechanisms and social norms (Rice and Sutton 1998). The former occurs when the action of an individual directly increases the benefit to other individuals of doing the same thing, while social norms within a group may lead an individual belonging to the group not to deviate from the perceived norms in order to avoid social sanctions. The data set in the present study provide an excellent opportunity to measure peer behaviour, since all individuals in every school-class included were surveyed. This allowed me to create for each individual a measure indicating the fraction of class-mates that smoke, which was used as an instrument. Moreover, pupils cannot decide which school or class to participate in and, thus, cannot "sort" themselves into schools or classes with pupils similar to themselves. In addition, parents are not able to choose which class within the school to send their child to. Finally, Swedish schools do not sort students across classes according to ability. In sum, this means that peer behaviour could at least to some extent be regarded as exogenous to smoking. Using peer smoking as instrument, I also assume that it affects individual smoking, but does not directly affect risk perceptions. $^{14}$

The second instrument considered was a variable measuring the respondent's general satisfaction with life. The rationale for this instrument is that smoking among adolescents has been found to be a coping factor for negative emotions and dissatisfaction (Nichter et al. 1997; Lloyd and Lucas 1998). In other words, smoking may be viewed as a tool to reduce these negative emotions. Consequently, being dissatisfied with life increases the probability of smoking. I also assume this variable to have no direct effect on risk perceptions. ${ }^{15}$

\footnotetext{
${ }^{12}$ This is a commonly used test for testing the suitability of instruments within the context of GMM (Baum et al. 2003).

${ }^{13}$ In order to allow for arbitrary heteroscedasticity, I used a version of the test allowing for robust estimation, the $C$-statistic (Baum et al. 2003).

${ }^{14}$ There may exist other mechanisms through which peer smoking may affect risk perceptions, though. For instance, peer smoking may signal something about the risks of smoking, with a higher fraction of peers smoking signaling lower risks. To my knowledge, there is no prior research on the issue.

${ }^{15}$ As pointed out by an anonymous referee, this assumption may be somewhat strong. The assumption may fail if, for instance, depressed people are less optimistic about their future prospects and therefore have higher risk perceptions. This would suggest, however, that depressed people smoke less than nondepressed people, which seems not to be the case.
}

Springer 
The effect of risk perceptions on the dichotomous smoking decision was analysed with a standard probit-model. Whether or not instrumental variables techniques have to be employed also in this case depend on the results from the regressions on risk perception. IV-methods would have to be utilised if smoking were found to have an independent effect on risk perceptions, also when controlling for the endogeneity of smoking.

Finally, the smoking intensity equation was estimated. Since the different categories of smoking intensity were categorical, we employed an ordered-probit model (Greene 2000). Here, the sample was restricted to smokers, and the variable took on values ranging from 1 to 6 .

\section{Results}

\subsection{Smoking-mortality risk perceptions}

In Table 2, descriptive data on smoking-mortality risk perceptions for the full sample, for different age groups, and by smoking status are shown. As shown in the table, the average perceived smoking mortality risk in the full sample was 0.46 . There were significant differences, however, between the age groups. Among the youngest individuals, ages 15-16, the average figure was 0.47 , whereas the corresponding figure among the oldest age group, ages $17-18$, was 0.43 . The same pattern was obtained also when examining smokers and non-smokers separately, as shown in columns 3 and 4 of Table 2. Such age differences have been attributed to variation in the information received across different cohorts (Viscusi 1991). Descriptive results did indeed confirm that information from media sources was more common among the younger age group in our sample.

Regarding gender differences, the results in Table 2 suggest that females perceive the risks as greater than males. The mean estimate for women was 0.47 , whereas the corresponding estimate for men was 0.44 . The gender difference was statistically significant for the full sample, and for both smokers and non-smokers.

Finally, Table 2 shows that the difference in perceived risk between smokers $(0.42)$ and non-smokers $(0.48)$ is quite large. The same pattern was found for all age

Table 2 Variations in mean smoking mortality risk perception with age and smoking status. Mean of risk perceptions (sd.) by age group ${ }^{\mathrm{a}}$

\begin{tabular}{llll}
\hline Age group & Full sample & Smokers & Non-smokers \\
\hline Ages 15-16 & $0.471(0.269)$ & $0.425(0.275)$ & $0.477(0.269)$ \\
Ages 17-18 & $0.435(0.273)$ & $0.384(0.264)$ & $0.444(0.273)$ \\
All ages & $0.456(0.272)$ & $0.406(0.270)$ & $0.464(0.271)$ \\
Men, all ages & $0.439(0.283)$ & $0.376(0.282)$ & $0.446(0.282)$ \\
Women, all ages & $0.474(0.260)$ & $0.425(0.261)$ & $0.483(0.258)$ \\
Observations & 8,592 & 1,113 & 7,398 \\
\hline
\end{tabular}

\footnotetext{
${ }^{a}$ The differences in mean risk perceptions between $15-16$ and 17-18 year olds are statistically significant for smokers, non-smokers, and for the full sample. This is also true for the gender differences observed for the different categories. Finally, the differences in risk perceptions between smokers and non-smokers are statistically significant for both age groups, for men and women, and for the full sample.
} 
groups and for both men and women. The differences revealed were statistically significant.

The mean perceived mortality risk of 0.46 is quite close to prior estimates from a number of US surveys, where the perceived risk varied between 0.50 and 0.54 (Viscusi 2002). In the latter surveys, the mean perceived mortality risk among smokers ranged from 0.42 to 0.47 , compared to 0.42 in the present study. The differences by gender and age are also similar to those commonly found in studies on smoking risk perceptions (e.g. Viscusi 1991; Lundborg and Lindgren 2004; Liu and Hsieh 1995).

While the "true" smoking mortality risk is obviously unknown, current estimates indicate a risk of $0.18-0.36$ (Viscusi 2002). Using this interval as our measure of objective risk, we can examine the potential bias in our subjective risk perceptions. Table 3 shows the distribution of perceived smoking mortality risk for the full sample and for smokers and non-smokers separately. The results show that more than $60 \%$ of the sample believe that the risk is higher than the upper boundary of 0.36 . Moreover, less than $20 \%$ believe that the risk is lower than 0.20 , suggesting that the overwhelming majority of the sample respondents either have correct beliefs or overestimate the risk. The pattern does not change to any radical extent when analysing smokers in isolation. Less than $25 \%$ of smokers believe that the risk is below 0.20 , compared to roughly $18 \%$ among non-smokers. These patterns are surprisingly similar to the ones found in other studies using the same question format. Viscusi (2002) reports findings from a survey where 16\% of adults believed that the smoking mortality risk was below 0.20 . Among smokers, the corresponding figure was $23 \%$.

\subsection{Smoking addictiveness perceptions}

Table 4 shows perceived addictiveness of smoking, broken down across the same dimensions as the perceived smoking mortality risk in Table 2. The mean estimate of perceived addictiveness was 0.68 , suggesting that the average respondent believed that $68 \%$ of smokers trying to quit would not succeed. As revealed from the first

Table 3 Distribution of smoking mortality risk perceptions

\begin{tabular}{llll}
\hline & All respondents & Smokers & Non-smokers \\
\hline Risk $<0.05$ & 0.036 & 0.064 & 0.031 \\
$0.05 \leq$ Risk $<0.10$ & 0.043 & 0.051 & 0.042 \\
$0.10 \leq$ Risk $<0.20$ & 0.108 & 0.131 & 0.104 \\
$0.20 \leq$ Risk $<0.30$ & 0.120 & 0.126 & 0.119 \\
$0.30 \leq$ Risk $<0.40$ & 0.095 & 0.101 & 0.094 \\
$0.40 \leq$ Risk $<0.50$ & 0.085 & 0.082 & 0.085 \\
$0.50 \leq$ Risk $<0.60$ & 0.169 & 0.179 & 0.168 \\
$0.60 \leq$ Risk $<0.70$ & 0.082 & 0.065 & 0.085 \\
$0.70 \leq$ Risk $<0.80$ & 0.113 & 0.089 & 0.117 \\
$0.80 \leq$ Risk $<0.90$ & 0.070 & 0.054 & 0.073 \\
$0.90 \leq$ Risk $<1$ & 0.062 & 0.038 & 0.065 \\
Risk $=1$ & 0.017 & 0.022 & 0.016 \\
Observations & 8,592 & 1,113 & 7,398 \\
\hline
\end{tabular}


Table 4 Variations in mean smoking addictiveness risk perception with age and smoking status. Mean of risk perceptions (sd.) by age group ${ }^{\mathrm{a}}$

\begin{tabular}{llll}
\hline Age group & All respondents & Smokers & Non-smokers \\
\hline Ages 15-16 & $0.680(0.219)$ & $0.639(0.244)$ & $0.686(0.214)$ \\
Ages 17-18 & $0.672(0.217)$ & $0.643(0.232)$ & $0.677(0.214)$ \\
All ages & $0.677(0.218)$ & $0.641(0.238)$ & $0.683(0.214)$ \\
Men, all ages & $0.691(0.224)$ & $0.647(0.250)$ & $0.696(0.226)$ \\
Women, all ages & $0.663(0.211)$ & $0.637(0.232)$ & $0.668(0.206)$ \\
Observations & 8,576 & 1,113 & 7,398 \\
\hline
\end{tabular}

${ }^{a}$ No statistically significant age differences in mean addictiveness-risk perceptions were obtained. Statistically significant gender differences were found for the full sample and the sample of non-smokers, but not for the sample of smokers. The differences in mean perceived addictiveness-risk between smokers and non-smokers were statistically significant for the full sample, for both age groups, and for both men and women.

column, perceptions regarding addictiveness varied only to a small extent between age groups. In fact, none of the differences were statistically significant. The results do show, however, that perceptions of addictiveness varied by gender. Somewhat surprisingly, females perceived smoking as significantly less addictive than males did. This difference was statistically significant for the full sample and for the sample of non-smokers. In comparing smokers and non-smokers, the results showed that smokers perceived smoking to be less addictive than non-smokers did. This difference was significant for the full sample, for both age groups, and for both men and women.

Obtaining objective quantitative information on the addictiveness of smoking is difficult. The quit ratio, i.e. the ratio of former smokers to ever-smokers, may give some indication. In the US, there are about as many quitters as smokers (Hughes 2003). In our sample, former smokers constitute $37 \%$ of the ever smoker group. The quit ratio is not very useful for our purposes, though, since it does not tell us the percentage of smokers that have tried to quit that are successful.

Instead, in order to get a sense of the addictiveness of smoking, one may look at data on quitting and quitting attempts. In Hymowitz et al. (1997), a sample of adult smokers were followed for 5 years. During this period, $67 \%$ of the smokers made at least one serious attempt to stop smoking and at the follow-up 33\% of these had quit smoking. More recent evidence is presented in Hyland et al. (2006), following smokers making quit attempts in four countries. Between waves 1 and 2, conducted 8-10 months apart, 36\% of smokers made at least one attempt to quit. At the followup, $25 \%$ of those who made a quit attempt had stopped smoking. The rates were rather similar in the UK, US, Canada, and Australia. Focusing on a younger sample, Tucker et al. (2005) followed smokers aged 23 until age 29. At age 29, 76\% expressed that they had made an attempt to quit, since the last assessment at age 23 . Out of these, 26\% had quit for 6 months or longer between ages 23-29.

The results cited above concern quitting and quitting attempts during limited periods and future relapses into smoking were not accounted for. During their lifetime, however, most smokers make multiple attempts to quit and it has been estimated that about $50 \%$ of smokers trying to quit eventually succeed (Hughes 2003). Table 5 shows the distribution of perceptions of addictiveness in our sample. 
Table 5 Distribution of smoking addictiveness perceptions

\begin{tabular}{llll}
\hline & All respondents & Smokers & Non-smokers \\
\hline Risk $<0.05$ & 0.011 & 0.025 & 0.009 \\
$0.05 \leq$ Risk $<0.10$ & 0.002 & 0.004 & 0.002 \\
$0.10 \leq$ Risk $<0.20$ & 0.016 & 0.022 & 0.015 \\
$0.20 \leq$ Risk $<0.30$ & 0.031 & 0.036 & 0.030 \\
$0.30 \leq$ Risk $<0.40$ & 0.030 & 0.034 & 0.029 \\
$0.40 \leq$ Risk $<0.50$ & 0.041 & 0.045 & 0.040 \\
$0.50 \leq$ Risk $<0.60$ & 0.170 & 0.211 & 0.164 \\
$0.60 \leq$ Risk $<0.70$ & 0.100 & 0.092 & 0.101 \\
$0.70 \leq$ Risk $<0.80$ & 0.173 & 0.150 & 0.176 \\
$0.80 \leq$ Risk $<0.90$ & 0.205 & 0.180 & 0.209 \\
$0.90 \leq$ Risk $<1$ & 0.215 & 0.191 & 0.218 \\
Risk $=1$ & 0.007 & 0.011 & 0.006 \\
Observations & 8,592 & 1,113 & 7,398 \\
\hline
\end{tabular}

Taking the objective figure of the proportion of smokers that succeed in quitting being $50 \%$, our sample seems to be well aware of the addictiveness of smoking, and there is even a tendency to overestimate the addictiveness. Only about $12 \%$ of the full sample believed that less than half of all smokers trying to quit would fail to do so. About $60 \%$ of the sample believed that $70 \%$ or more of smokers trying to quit would fail.

Quantitative estimates of addictiveness perceptions are rare in the literature, whereas qualitative assessments are common. An exception is the Annenberg Survey, where a question similar to the one used in this study was asked, let alone with a different denominator (Jamieson and Romer 2001). Their results are remarkably similar to the ones obtained in the current study; in the Annenberg Survey, the average respondent believed that 3.2 smokers out of 10 attempting to quit would succeed. ${ }^{16}$

\subsection{Correlation in perceptions}

In Table 6, mean perceived addictiveness at different levels of perceived smoking mortality is shown. The results allow us to examine whether individuals who believe the smoking mortality risk to be low also perceive the addictiveness of smoking to be low. This does not seem to be the case, however, and the results indicate no systematic relationship between perceived addictiveness and perceived smoking mortality risk. For instance, those who clearly underestimate the mortality risk of smoking, believing that fewer than 5 out of 100 smokers will die from smokingrelated illnesses, have about the same perceived addictiveness risk (0.69) as those who clearly overestimate the smoking mortality risk, believing that between 80 and

\footnotetext{
${ }^{16}$ In the Annenberg Survey, the question was framed as: "I would like you to imagine ten people your age who smoke a pack of cigarettes a day. All ten of these people say that they would like to quit in the next 5 years. How many of them do you think would actually quit permanently in the next 5 years?" (Weinstein et al. 2004).
}

望 Springer 
Table 6 Distribution of smoking addictiveness perceptions by different categories of perceived smoking mortality risk

\begin{tabular}{ll}
\hline Smoking mortality risk & Perceived addictiveness, all respondents \\
\hline Risk $<0.05$ & 0.691 \\
$0.05 \leq$ Risk $<0.10$ & 0.676 \\
$0.10 \leq$ Risk $<0.20$ & 0.677 \\
$0.20 \leq$ Risk $<0.30$ & 0.671 \\
$0.30 \leq$ Risk $<0.40$ & 0.692 \\
$0.40 \leq$ Risk $<0.50$ & 0.668 \\
$0.50 \leq$ Risk $<0.60$ & 0.681 \\
$0.60 \leq$ Risk $<0.70$ & 0.678 \\
$0.70 \leq$ Risk $<0.80$ & 0.680 \\
$0.80 \leq$ Risk $<0.90$ & 0.676 \\
$0.90 \leq$ Risk $<1$ & 0.674 \\
Risk $=1$ & 0.613 \\
Observations & 8,592 \\
\hline
\end{tabular}

90 smokers out of 100 will die. The exception from the general pattern is the category that believes that the smoking mortality risk is equal to 1 . This group has a somewhat lower perception of the addictiveness of smoking, 0.61 .

\subsection{Perceptions by smoking intensity}

In Table 7, perceptions of addictiveness and mortality risk by different categories of smoking intensity are shown. The heaviest smokers, who supposedly are at highest risk of smoking-related mortality, perceive, on average, a smoking-death probability of 0.38 , which is almost 10 percentage points lower than the corresponding figure for non-smokers. Statistically significant differences were to be found between the non-smoking category and the categories $1-2,3-6,7-10$, cigarettes per day. The differences in perceived risks between different categories of smokers, however, were never statistically significant.

The average perceived addictiveness among those smoking 1-2 cigarettes per day, 0.65 , was about the same as the perceived addictiveness among those smoking more than 20 cigarettes per day, 0.64. No statistically significant differences in

Table 7 Variations in mean smoking mortality and addictiveness risk perception with smoking intensity

\begin{tabular}{llll}
\hline Smoking category & Mortality & Addictiveness & $N$ \\
\hline Do not smoke & $0.468(0.270)$ & $0.686(0.213)$ & 6,566 \\
$1-2$ cigarettes & $0.422(0.283)$ & $0.650(0.221)$ & 503 \\
3-6 cigarettes & $0.400(0.255)$ & $0.637(0.231)$ & 514 \\
$7-10$ cigarettes & $0.421(0.268)$ & $0.632(0.231)$ & 321 \\
$11-16$ cigarettes & $0.415(0.274)$ & $0.647(0.240)$ & 204 \\
$17-20$ cigarettes & $0.412(0.300)$ & $0.683(0.227)$ & 89 \\
20 or more cigarettes & $0.375(0.344)$ & $0.638(0.357)$ & 50 \\
Total & $0.457(0.272)$ & $0.678(0.218)$ & 8,247 \\
\hline
\end{tabular}

Mean of risk perceptions (sd.) by age group 
perceived addictiveness were found between the different categories of smokers. The differences between the non-smoking category and the categories $1-2,3-6$, and 7-10 cigarettes per day were statistically significant, however.

\subsection{Regressions on the perceived smoking mortality risk}

Table 8 presents the results from the regressions on perceived smoking-mortality risk. In the first column of the table, the potentially endogenous smoker variable is left out, whereas in column 2 the smoker variable is included but treated as exogenous. Column 3 presents the results, when taking into account the potential endogeneity of the smoker variable.

A number of variables showed consistent effects across all three specifications. Younger age, being female, and living with both parents were associated with significantly higher perceived smoking-mortality risk. Higher income showed a negative, and significant, correlation with risk perceptions.

Regarding information sources, the results were again quite similar across the three specifications in Table 8 . The only significant information source variables were having searched information on one's own and having received information by a teacher, which were associated with significantly higher perceptions, and having received information from another adult at school, which was associated with lower perceptions. Own information search was associated with an increase in the perceived mortality risk by 0.032 , which was double the size of the relatively modest association between having receiving information from a teacher and risk beliefs. ${ }^{17}$ Interestingly, the finding of a positive correlation between information by teachers and risk perceptions was in contrast to the finding in Lundborg and Lindgren (2002), where education about alcohol, narcotics, and drugs at school was found to be negatively related to alcoholism risk perceptions. ${ }^{18}$

As shown in the second column of Table 8, being a smoker showed a significant and negative correlation with risk perceptions, when the former was treated as exogenous. This is consistent with several mechanisms, as discussed in Section 4. It remains, however, to examine the effect of being a smoker when treating the latter as endogenous.

In the specification treating smoking as endogenous, smoking was no longer statistically significant, suggesting that smoking had no independent effect on smoking risk perceptions (see column 3 of Table 8). Having established that the

\footnotetext{
${ }^{17}$ Searching information by one's own may for many teenagers mean coming into contact with official, government-sponsored, Swedish information sites, such as the website "Tobaksfakta," which provides smoking related information (Tobaksfakta 2006). A common claim on such information sites is that half of all smokers who begin smoking during their teens will die from a smoking-related disease. "Tobaksfakta" is a joint project by the Swedish National Institute of Public Health, The Swedish Cancer Society, and the Swedish Heart and Lung Society.

${ }^{18}$ When interpreting the coefficients of the information source variables, one should bear in mind that causation is difficult to establish. Having received information from a particular source may, for instance, be related to characteristics unobserved to the analyst. Establishing causality would require experimental methods, or at least some suitable instrument for the various information sources, which is beyond the scope of the present study.
} 
Table 8 Regression on perceived smoking mortality risk

\begin{tabular}{|c|c|c|c|}
\hline & Smoker variable excluded & Smoker exogenous & Smoker endogenous \\
\hline Female & $\begin{array}{l}0.030 \\
(4.76)^{* *}\end{array}$ & $\begin{array}{l}0.033 \\
(5.21)^{* *}\end{array}$ & $\begin{array}{l}0.031 \\
(4.68)^{* *}\end{array}$ \\
\hline Grade 9 & $\begin{array}{l}0.023 \\
(3.06)^{* *}\end{array}$ & $\begin{array}{l}0.022 \\
(2.81)^{* *}\end{array}$ & $\begin{array}{l}0.023 \\
(2.99)^{* *}\end{array}$ \\
\hline Born in Sweden & $\begin{array}{l}-0.007 \\
(0.55)\end{array}$ & $\begin{array}{l}-0.008 \\
(0.68)\end{array}$ & $\begin{array}{l}-0.007 \\
(0.58)\end{array}$ \\
\hline Living with both parents & $\begin{array}{l}0.023 \\
(3.37)^{* *}\end{array}$ & $\begin{array}{l}0.017 \\
(2.55)^{*}\end{array}$ & $\begin{array}{l}0.023 \\
(3.10)^{* *}\end{array}$ \\
\hline Mother has university education & $\begin{array}{l}0.006 \\
(0.74)\end{array}$ & $\begin{array}{l}0.006 \\
(0.69)\end{array}$ & $\begin{array}{l}0.007 \\
(0.89)\end{array}$ \\
\hline Don't know mother's education & $\begin{array}{l}0.016 \\
(1.40)\end{array}$ & $\begin{array}{l}0.015 \\
(1.30)\end{array}$ & $\begin{array}{l}0.014 \\
(1.20)\end{array}$ \\
\hline Father has university education & $\begin{array}{l}0.013 \\
(1.62)\end{array}$ & $\begin{array}{l}0.011 \\
(1.47)\end{array}$ & $\begin{array}{l}0.013 \\
(1.62)\end{array}$ \\
\hline Don't know father's education & $\begin{array}{l}-0.007 \\
(0.66)\end{array}$ & $\begin{array}{l}-0.004 \\
(0.41)\end{array}$ & $\begin{array}{l}-0.006 \\
(0.58)\end{array}$ \\
\hline Income category 2 & $\begin{array}{l}-0.022 \\
(2.36)^{*}\end{array}$ & $\begin{array}{l}-0.021 \\
(2.26)^{*}\end{array}$ & $\begin{array}{l}-0.020 \\
(2.20)^{*}\end{array}$ \\
\hline Income category 3 & $\begin{array}{l}-0.040 \\
(4.58)^{* *}\end{array}$ & $\begin{array}{l}-0.036 \\
(4.16)^{* *}\end{array}$ & $\begin{array}{l}-0.038 \\
(4.37)^{* *}\end{array}$ \\
\hline Income category 4 & $\begin{array}{l}-0.052 \\
(4.06)^{* *}\end{array}$ & $\begin{array}{l}-0.048 \\
(3.75)^{* *}\end{array}$ & $\begin{array}{l}-0.050 \\
(3.87)^{* *}\end{array}$ \\
\hline Income category 5 & $\begin{array}{l}-0.077 \\
(4.52)^{* *}\end{array}$ & $\begin{array}{l}-0.074 \\
(4.41)^{* *}\end{array}$ & $\begin{array}{l}-0.079 \\
(4.56)^{* *}\end{array}$ \\
\hline Income category 6 & $\begin{array}{l}-0.055 \\
(2.58)^{*}\end{array}$ & $\begin{array}{l}-0.052 \\
(2.46)^{*}\end{array}$ & $\begin{array}{l}-0.055 \\
(2.57)^{*}\end{array}$ \\
\hline Income category 7 & $\begin{array}{l}-0.049 \\
(3.55)^{* *}\end{array}$ & $\begin{array}{l}-0.041 \\
(2.95)^{* *}\end{array}$ & $\begin{array}{l}-0.047 \\
(3.23)^{* *}\end{array}$ \\
\hline $\begin{array}{l}\text { Information searched by the respondent } \\
\mathrm{him} / \text { herself }\end{array}$ & $\begin{array}{l}0.032 \\
(3.27)^{* *}\end{array}$ & $\begin{array}{l}0.032 \\
(3.28)^{* *}\end{array}$ & $\begin{array}{l}0.033 \\
(3.28)^{* *}\end{array}$ \\
\hline Information by teacher & $\begin{array}{l}0.016 \\
(2.32)^{*}\end{array}$ & $\begin{array}{l}0.014 \\
(2.01)^{*}\end{array}$ & $\begin{array}{l}0.016 \\
(2.27)^{*}\end{array}$ \\
\hline Information by other adult at school & $\begin{array}{l}-0.012 \\
(1.89)\end{array}$ & $\begin{array}{l}-0.016 \\
(2.42)^{*}\end{array}$ & $\begin{array}{l}-0.013 \\
(2.00)^{*}\end{array}$ \\
\hline Information by parents & $\begin{array}{l}0.011 \\
(1.64)\end{array}$ & $\begin{array}{l}0.012 \\
(1.72)\end{array}$ & $\begin{array}{l}0.011 \\
(1.53)\end{array}$ \\
\hline Information by siblings & $\begin{array}{l}-0.010 \\
(0.82)\end{array}$ & $\begin{array}{l}-0.008 \\
(0.68)\end{array}$ & $\begin{array}{l}-0.009 \\
(0.70)\end{array}$ \\
\hline Information by friends & $\begin{array}{l}0.013 \\
(1.29)\end{array}$ & $\begin{array}{l}0.017 \\
(1.66)\end{array}$ & $\begin{array}{l}0.015 \\
(1.40)\end{array}$ \\
\hline Information by other adults & $\begin{array}{l}-0.002 \\
(0.27)\end{array}$ & $\begin{array}{l}-0.002 \\
(0.20)\end{array}$ & $\begin{array}{l}-0.003 \\
(0.34)\end{array}$ \\
\hline Information by $\mathrm{TV}$, magazines or radio & $\begin{array}{l}0.005 \\
(0.72)\end{array}$ & $\begin{array}{l}0.004 \\
(0.57)\end{array}$ & $\begin{array}{l}0.003 \\
(0.45)\end{array}$ \\
\hline Information by other sources & $\begin{array}{l}0.019 \\
(1.52)\end{array}$ & $\begin{array}{l}0.018 \\
(1.49)\end{array}$ & $\begin{array}{l}0.019 \\
(1.56)\end{array}$ \\
\hline Smoker & & $\begin{array}{l}-0.053 \\
(5.71)^{* *}\end{array}$ & $\begin{array}{l}-0.009 \\
(0.30)\end{array}$ \\
\hline Constant & $\begin{array}{l}0.421 \\
(25.58) * *\end{array}$ & $\begin{array}{l}0.433 \\
(26.33) * *\end{array}$ & $\begin{array}{l}0.424 \\
(24.35)^{* *}\end{array}$ \\
\hline $\begin{array}{l}\text { Observations } \\
\text { R-squared }\end{array}$ & $\begin{array}{l}8,304 \\
0.02\end{array}$ & $\begin{array}{l}8,231 \\
0.02\end{array}$ & 8,181 \\
\hline
\end{tabular}

Regressions with smoker excluded and smoker treated as exogenous/endogenous Robust $t$-statistics in parentheses

*significant at $5 \%, * *$ significant at $1 \%$ 
instruments were decent, the exogeneity of smoking could be tested. ${ }^{19}$ The test yielded a $C$-statistic of $2.54(p=0.12)$, which was too large to make us comfortable in accepting the null hypothesis. This suggested that the specification treating smoking as endogenous indeed was the preferred one. This is an expected result, since the health effects of smoking are unlikely to have yet occurred in our young sample and smoking should therefore not affect mortality risk perceptions. Instead, the effect obtained when treating smoking as exogenous may most likely be a result of reverse causality, running from risk perceptions to smoking. The IV results should be interpreted with some caution, though, since the validity of the instruments could be questioned, as discussed in Section 3.

\subsection{Regressions on perceived addictiveness of smoking}

In Table 9, regressions on the perceived addictiveness of smoking are shown. None of the information source variables and few of the other variables appeared statistically significant. Notable is that being female showed a statistically significant and negative correlation with the perceived addictiveness of smoking. A similar result was found for those living with both parents in the specifications where smoking status was included. As shown in the second column of Table 9, smoking was negatively and significantly associated with the perceived addictiveness of smoking, when the former was treated as exogenous.

The result that none of the information source variables affected the perception of addictiveness may have several reasons. The main reason may be that most efforts to inform the public about the risks of smoking have focused on the mortality and morbidity risks of smoking. As shown in Section 2, on-label warnings have only rarely included texts referring to the potential addictiveness of smoking. I also checked for possible multicollinearity problems that may explain the joint insignificance of the information variables. Examining the correlation matrix, however, revealed that none of the correlation coefficients between any pair of information variables exceeded 0.39 .

Column 3 presents the results when treating smoking as an endogenous variable. In this specification, smoking still showed a statistically significant and negative correlation with the perceived addictiveness of smoking. ${ }^{20}$ The exogeneity test yielded a $C$-statistic of $0.71(p=0.70)$, suggesting that the exogeneity of smoking could not be rejected. This suggested that the specification treating smoking as

\footnotetext{
${ }^{19}$ When treating the smoker variable as endogenous, I first considered whether it was necessary to use the IV-GMM method. The Pagan-Hall test rejected the hypothesis that the errors were homoscedastic, suggesting that IV-GMM was the preferred method. Next, I considered the relevance of the instruments. The $F$-test of joint significance yielded an $F$-statistics of $545(p<0.01)$, suggesting that the instruments could not be regarded as "weak" (Staiger and Stock 1997). Moreover, the partial $R^{2}$ was 0.12 , well above the rule of thumb of 0.01 . Next, I tested the exclusion restrictions. The test of overidentifying restrictions yielded a low $J$-statistic $(p<0.01)$, suggesting that the assumption of valid exclusion restrictions could not be rejected.

${ }^{20}$ Again, the Pagan-Hall indicated that the IV-GMM method was the preferred one. The power of the instruments in predicting smoking was already established. The test of overidentifying restrictions could not reject the hypothesis of valid exclusion restrictions.
} 
Table 9 Regression on perceived smoking addictiveness

\begin{tabular}{|c|c|c|c|}
\hline & Smoker variable excluded & Smoker exogenous & Smoker endogenous \\
\hline Female & $\begin{array}{l}-0.027 \\
(5.57)^{* *}\end{array}$ & $\begin{array}{l}-0.025 \\
(5.10)^{* *}\end{array}$ & $\begin{array}{l}-0.025 \\
(5.00)^{* *}\end{array}$ \\
\hline Grade 9 & $\begin{array}{l}0.009 \\
(1.48)\end{array}$ & $\begin{array}{l}0.007 \\
(1.28)\end{array}$ & $\begin{array}{l}0.007 \\
(1.23)\end{array}$ \\
\hline Born in Sweden & $\begin{array}{l}-0.009 \\
(1.07)\end{array}$ & $\begin{array}{l}-0.011 \\
(1.28)\end{array}$ & $\begin{array}{l}-0.010 \\
(1.19)\end{array}$ \\
\hline Living with both parents & $\begin{array}{l}-0.010 \\
(1.80)\end{array}$ & $\begin{array}{l}-0.014 \\
(2.62)^{* *}\end{array}$ & $\begin{array}{l}-0.014 \\
(2.52)^{*}\end{array}$ \\
\hline Mother has university education & $\begin{array}{l}-0.002 \\
(0.40)\end{array}$ & $\begin{array}{l}-0.003 \\
(0.54)\end{array}$ & $\begin{array}{l}-0.003 \\
(0.49)\end{array}$ \\
\hline Don't know mother's education & $\begin{array}{l}0.007 \\
(0.75)\end{array}$ & $\begin{array}{l}0.006 \\
(0.72)\end{array}$ & $\begin{array}{l}0.006 \\
(0.64)\end{array}$ \\
\hline Father has university education & $\begin{array}{l}-0.001 \\
(0.24)\end{array}$ & $\begin{array}{l}-0.002 \\
(0.34)\end{array}$ & $\begin{array}{l}-0.002 \\
(0.39)\end{array}$ \\
\hline Don't know father's education & $\begin{array}{l}-0.014 \\
(1.66)\end{array}$ & $\begin{array}{l}-0.011 \\
(1.31)\end{array}$ & $\begin{array}{l}-0.010 \\
(1.20)\end{array}$ \\
\hline Income category 2 & $\begin{array}{l}-0.009 \\
(1.34)\end{array}$ & $\begin{array}{l}-0.009 \\
(1.23)\end{array}$ & $\begin{array}{l}-0.008 \\
(1.17)\end{array}$ \\
\hline Income category 3 & $\begin{array}{l}-0.007 \\
(1.07)\end{array}$ & $\begin{array}{l}-0.005 \\
(0.68)\end{array}$ & $\begin{array}{l}-0.005 \\
(0.69)\end{array}$ \\
\hline Income category 4 & $\begin{array}{l}-0.010 \\
(0.98)\end{array}$ & $\begin{array}{l}-0.007 \\
(0.70)\end{array}$ & $\begin{array}{l}-0.008 \\
(0.78)\end{array}$ \\
\hline Income category 5 & $\begin{array}{l}-0.025 \\
(1.86)\end{array}$ & $\begin{array}{l}-0.021 \\
(1.57)\end{array}$ & $\begin{array}{l}-0.021 \\
(1.56)\end{array}$ \\
\hline Income category 6 & $\begin{array}{l}0.006 \\
(0.40)\end{array}$ & $\begin{array}{l}0.009 \\
(0.56)\end{array}$ & $\begin{array}{l}0.009 \\
(0.59)\end{array}$ \\
\hline Income category 7 & $\begin{array}{l}0.013 \\
(1.14)\end{array}$ & $\begin{array}{l}0.018 \\
(1.54)\end{array}$ & $\begin{array}{l}0.018 \\
(1.47)\end{array}$ \\
\hline $\begin{array}{l}\text { Information searched by the respondent } \\
\mathrm{him} / \text { herself }\end{array}$ & $\begin{array}{l}-0.010 \\
(1.24)\end{array}$ & $\begin{array}{l}-0.010 \\
(1.13)\end{array}$ & $\begin{array}{l}-0.008 \\
(0.92)\end{array}$ \\
\hline Information by teacher & $\begin{array}{l}-0.005 \\
(0.83)\end{array}$ & $\begin{array}{l}-0.006 \\
(1.01)\end{array}$ & $\begin{array}{l}-0.006 \\
(1.08)\end{array}$ \\
\hline Information by other adult at school & $\begin{array}{l}-0.002 \\
(0.30)\end{array}$ & $\begin{array}{l}-0.003 \\
(0.63)\end{array}$ & $\begin{array}{l}-0.003 \\
(0.60)\end{array}$ \\
\hline Information by parents & $\begin{array}{l}-0.005 \\
(1.01)\end{array}$ & $\begin{array}{l}-0.005 \\
(0.86)\end{array}$ & $\begin{array}{l}-0.004 \\
(0.82)\end{array}$ \\
\hline Information by siblings & $\begin{array}{l}-0.009 \\
(0.87)\end{array}$ & $\begin{array}{l}-0.009 \\
(0.83)\end{array}$ & $\begin{array}{l}-0.009 \\
(0.82)\end{array}$ \\
\hline Information by friends & $\begin{array}{l}-0.009 \\
(1.17)\end{array}$ & $\begin{array}{l}-0.005 \\
(0.73)\end{array}$ & $\begin{array}{l}-0.005 \\
(0.70)\end{array}$ \\
\hline Information by other adults & $\begin{array}{l}0.009 \\
(1.26)\end{array}$ & $\begin{array}{l}0.008 \\
(1.22)\end{array}$ & $\begin{array}{l}0.008 \\
(1.12)\end{array}$ \\
\hline Information by $\mathrm{TV}$, magazines or radio & $\begin{array}{l}0.002 \\
(0.46)\end{array}$ & $\begin{array}{l}0.002 \\
(0.44)\end{array}$ & $\begin{array}{l}0.002 \\
(0.37)\end{array}$ \\
\hline Information by other sources & $\begin{array}{l}0.015 \\
(1.49)\end{array}$ & $\begin{array}{l}0.015 \\
(1.47)\end{array}$ & $\begin{array}{l}0.015 \\
(1.46)\end{array}$ \\
\hline Smoker & & $\begin{array}{l}-0.042 \\
(5.04)^{* *}\end{array}$ & $\begin{array}{l}-0.038 \\
(1.71)\end{array}$ \\
\hline Constant & $\begin{array}{l}0.285 \\
(22.69)^{* *}\end{array}$ & $\begin{array}{l}0.277 \\
(21.81)^{* *}\end{array}$ & $\begin{array}{l}0.277 \\
(20.57)^{* *}\end{array}$ \\
\hline Observations & 8,304 & 8,231 & 8,181 \\
\hline R-squared & 0.01 & 0.01 & \\
\hline
\end{tabular}

Regressions with smoker excluded and smoker treated as exogenous/endogenous

Robust $t$-statistics in parentheses

*significant at $5 \%, * *$ significant at $1 \%$ 
exogenous, as presented in column 2, was the preferred one. Again, the IV results should be interpreted with some caution, however.

\subsection{Smoker equation}

Next, the effect of risk perceptions on the binary smoking decision was estimated. Here, mortality risk perception was treated as exogenous as the results from the risk perception equation showed that being a smoker showed no independent effect on smoking risk perceptions, once taking into account the endogeneity of smoking. I also treat perceptions of addictiveness as exogenous, due to lack of available instruments, i.e. variables that affect perceptions of addictiveness but not directly smoking behaviour. ${ }^{21}$

According to the first column of Table 10, the perception of addictiveness was significantly related to the probability of being smoker. The more addictive the respondent thought smoking was, the lower the probability of him/her being a smoker. Moreover, perceived mortality risk showed a negative and significant correlation with the smoking probability. Consequently, both types of perception affected smoking behaviour in the expected direction. ${ }^{22}$

Several of the information-source variables showed significant effects on the smoking probability after controlling for risk perceptions. Information received from teachers or other adults at school showed a significant and negative association with smoking probability. This is not that surprising, since other aspects of smoking not related to mortality or addictiveness may have been included in the information efforts. Such information may, for instance, be related to the effects of smoking on short-term outcomes, such as yellowed teeth and bad skin, or reduced fertility. It may also have been related to some of the potential outcomes of smoking, for instance showing pictures of damaged lungs etc. Such information may not affect risk perceptions, but rather the perceived severity of the potential outcome, thereby affecting the perceived costs of smoking. The opposite result was found for information received from parents and pals, possibly reflecting reverse causality, since becoming a smoker may cause parents and friends to inform you about the negative aspects of smoking. In this respect, information from teachers and media may be more "exogenous" sources of information. Other types of information sources showed no significant effect on the smoking probability.

Among the other variables, income and being female showed a significant and positive correlation with the smoking probability. The income effect was strong and belonging to the highest income category increased the smoking probability by 15.4 percentage points compared to belonging to the lowest income category. Being younger, being born in Sweden, and living with both parents were associated with a significantly lower probability of being a smoker. The effect of the latter was

\footnotetext{
${ }^{21}$ Candidates as instruments would be smoking risk information sources. However, as will be shown, these showed an independent effect on smoking, after controlling for smoking risk perceptions, rendering them useless as instruments.

${ }^{22}$ In addition, the interactions between gender and risk perceptions were tested. No evidence, however, was obtained supporting differential responses to risk perceptions by gender, since the interaction terms were statistically insignificant.
} 
Table 10 Smoking and smoking intensity equation

\begin{tabular}{|c|c|c|}
\hline & Smoker equation & Smoking intensity equation \\
\hline Perceived mortality risk & $\begin{array}{l}-0.076 \\
(5.54)^{* *}\end{array}$ & $\begin{array}{l}-0.011 \\
(0.11)\end{array}$ \\
\hline Perceived addictiveness & $\begin{array}{l}-0.088 \\
(5.44)^{* *}\end{array}$ & $\begin{array}{l}-0.068 \\
(0.56)\end{array}$ \\
\hline Female & $\begin{array}{l}0.058 \\
(7.74)^{* *}\end{array}$ & $\begin{array}{l}0.011 \\
(0.19)\end{array}$ \\
\hline Grade 9 & $\begin{array}{l}-0.022 \\
(2.19)^{*}\end{array}$ & $\begin{array}{l}0.014 \\
(0.20)\end{array}$ \\
\hline Born in Sweden & $\begin{array}{l}-0.042 \\
(2.51)^{*}\end{array}$ & $\begin{array}{l}-0.161 \\
(1.75)\end{array}$ \\
\hline Living with both parents & $\begin{array}{l}-0.095 \\
(11.19)^{* *}\end{array}$ & $\begin{array}{l}-0.346 \\
(6.00)^{* *}\end{array}$ \\
\hline Mother has university education & $\begin{array}{l}-0.015 \\
(1.55)\end{array}$ & $\begin{array}{l}-0.288 \\
(3.92)^{* *}\end{array}$ \\
\hline Don't know mother's education & $\begin{array}{l}0.006 \\
(0.48)\end{array}$ & $\begin{array}{l}0.030 \\
(0.33)\end{array}$ \\
\hline Father has university education & $\begin{array}{l}-0.019 \\
(1.89)\end{array}$ & $\begin{array}{l}-0.035 \\
(0.44)\end{array}$ \\
\hline Don't know father's education & $\begin{array}{l}0.041 \\
(3.25)^{* *}\end{array}$ & $\begin{array}{l}0.057 \\
(0.70)\end{array}$ \\
\hline Income category 2 & $\begin{array}{l}0.017 \\
(1.31)\end{array}$ & $\begin{array}{l}-0.051 \\
(0.50)\end{array}$ \\
\hline Income category 3 & $\begin{array}{l}0.055 \\
(4.56)^{* *}\end{array}$ & $\begin{array}{l}0.101 \\
(1.06)\end{array}$ \\
\hline Income category 4 & $\begin{array}{l}0.081 \\
(4.35)^{* *}\end{array}$ & $\begin{array}{l}0.139 \\
(1.16)\end{array}$ \\
\hline Income category 5 & $\begin{array}{l}0.111 \\
(4.69)^{* *}\end{array}$ & $\begin{array}{l}0.183 \\
(1.17)\end{array}$ \\
\hline Income category 6 & $\begin{array}{l}0.067 \\
(2.50)^{*}\end{array}$ & $\begin{array}{l}0.163 \\
(1.08)\end{array}$ \\
\hline Income category 7 & $\begin{array}{l}0.154 \\
(7.84)^{* *}\end{array}$ & $\begin{array}{l}0.485 \\
(4.10)^{* *}\end{array}$ \\
\hline Information searched by the respondent him/herself & $\begin{array}{l}-0.002 \\
(0.15)\end{array}$ & $\begin{array}{l}-0.086 \\
(0.97)\end{array}$ \\
\hline Information by teacher & $\begin{array}{l}-0.031 \\
(3.59)^{* *}\end{array}$ & $\begin{array}{l}-0.025 \\
(0.41)\end{array}$ \\
\hline Information by other adult at school & $\begin{array}{l}-0.051 \\
(6.82)^{* *}\end{array}$ & $\begin{array}{l}-0.142 \\
(2.16)^{*}\end{array}$ \\
\hline Information by parents & $\begin{array}{l}0.024 \\
(2.98)^{* *}\end{array}$ & $\begin{array}{l}0.057 \\
(0.89)\end{array}$ \\
\hline Information by siblings & $\begin{array}{l}0.013 \\
(0.94)\end{array}$ & $\begin{array}{l}0.211 \\
(2.14)^{*}\end{array}$ \\
\hline Information by friends & $\begin{array}{l}0.059 \\
(4.90)^{* *}\end{array}$ & $\begin{array}{l}0.132 \\
(1.67)\end{array}$ \\
\hline Information by other adults & $\begin{array}{l}0.007 \\
(0.73)\end{array}$ & $\begin{array}{l}0.142 \\
(1.97)^{*}\end{array}$ \\
\hline Information by $\mathrm{TV}$, magazines or radio & $\begin{array}{l}-0.001 \\
(0.15)\end{array}$ & $\begin{array}{l}-0.158 \\
(2.40)^{*}\end{array}$ \\
\hline Information by other sources & $\begin{array}{l}0.001 \\
(0.06)\end{array}$ & $\begin{array}{l}0.095 \\
(0.81)\end{array}$ \\
\hline Observations & 8,231 & 1,625 \\
\hline
\end{tabular}

Probit and ordered probit model

Robust $z$-statistics in parentheses

*significant at $5 \%, * *$ significant at $1 \%$ 
especially strong as it lowered the probability of being a smoker by 9.5 percentage points.

\subsection{Smoking intensity equation}

Finally, in the second column of Table 10, I present the results from the smoking intensity equation. Here, the sample was restricted to smokers only.

Interestingly, the results showed that neither smoking mortality risk perceptions, nor perceptions of addictiveness were even close to being statistically significant. Thus, while risk perceptions strongly affected the probability of being a smoker, the amount of smoking among smokers was not significantly affected. A similar result was obtained in Lundborg and Lindgren (2004) in the case of lung cancer perceptions. Now, since it is well known that there exists a dose-response relationship between the intensity of smoking and the risk of developing various smoking-related illnesses, a rational smoker could be expected to take this into account when choosing his or her optimal level of smoking. The lack of such a relationship may therefore reflect a lack of such knowledge among smokers. This may reflect that information efforts have not considered the effects of different levels of smoking intensity on smoking related mortality and morbidity. An illustration of this is the fact that none of the on-label warnings in Sweden since the 1970s have concerned a dose-response relationship between smoking and mortality or morbidity.

Among the other variables, living with both parents and having a mother with a university education showed a statistically significant and negative correlation with smoking intensity, whereas belonging to the highest income category showed a statistically significant and positive correlation with smoking intensity.

As to information sources, having received information from $\mathrm{TV}$, radio or magazines and having received information from adults at school other than teachers were significantly and negatively correlated with smoking intensity. The opposite effect was obtained from having received information from siblings and from adults other than parents. Again, note that these results were obtained after controlling for risk perceptions, suggesting that these information sources again had effects on smoking above their potential effect on risk perceptions. None of the other information source variables were significant.

\section{Conclusions}

In this paper, I showed that an increase in the perceived addictiveness of smoking was associated with a lower probability of being a smoker. This finding is consistent with rational decision-making, since a higher perceived addictiveness should make experimentation with smoking more risky and increase perceived quitting costs.

A common claim is that the adverse health consequences of smoking are too far in the future to be influential for young people (World Bank 1999). This has also been suggested as an explanation for the low success of educational programmes concerning smoking (Weinstein et al. 2004). Another explanation commonly suggested is that teenage smokers simply deny the risks (Weinstein 1999). My results suggest that these are unlikely explanations, since one of the most obvious 
long-run risks - the risk of death from smoking - has a substantial impact on the smoking decisions made by teenagers.

The finding that the perceived addictiveness of smoking affects smoking behaviour has one important, and somewhat paradoxical, policy implication. Making quitting easier, for example by means of new smoking-cessation technologies, will allow more smokers to successfully quit smoking. This may lower the perceptions of the addictiveness of smoking, which, according to my results, may increase the number of people starting to smoke.

Acknowledgement The financial support of the Swedish Council for Working Life and Social Research, the Swedish National Institute for Public Health, NETSPAR, and Handelsbankens Forskningsstiftelser is gratefully acknowledged. The author thanks W. Kip Viscusi and Björn Lindgren for helpful comments.

\section{References}

Antoñanzas, Fernando, W. Kip Viscusi, Joan Rovira, Francisco J. Braña, Fabiola Portillo, and Irineu Carvalho. (2000). "Smoking Risks in Spain: Part I-Perceptions of Risks to the Smoker," Journal of Risk and Uncertainty 21, 161-186.

Baum, Christopher F., Mark E. Schaffer, and Steven Stillman. (2003). Instrumental Variables and GMM: Estimation and Testing. Working paper no. 545, Department of Economics, Boston College.

Bound, John, David A. Jaeger, and Regina M. Baker. (1995). "Problems with Instrumental Variables Estimation When the Correlation between the Instruments and the Endogenous Explanatory Variables is Weak," Journal of the American Statistical Association 90, 443-450.

Breusch, Trevor S., and Adrian R. Pagan. (1979). "A Simple Test for Heteroscedasticity and Random Coefficient Variation," Econometrica 47, 1287-1294.

CAN. (2004). Skolelevers Drogvanor 2003. Rapport nr 77. Stockholm: CAN.

Godfrey, Les G. (1978). “Testing for Multiplicative Heteroscedasticity,” Journal of Econometrics 8, 227-236.

Greene, William H. (2000). Econometric Analysis. New York: Prentice Hall.

Hansen, Lars P. (1982). "Large Sample Properties of Generalized Method of Moments Estimators," Econometrica 50, 1029-1054.

Hersch, Joni. (1998). "Teen Smoking Behavior and the Regulatory Environment," Duke Law Journal 47, 1143-1170.

Hughes, John R. (2003). "Motivating and Helping Smokers to Stop Smoking," Journal of General Internal Medicine 18, 1053-1057.

Hyland, Andrew, Borland, Ron, Li, Qiang, Yong, Hua H., McNeill, Ann, Fong, Geoffrey T., O’Connor, Richard J., and Cummings, Michael K. (2006). "Individual-level Predictors of Cessation Behaviours among Participants in the International Tobacco Control (ITC) Four Country Survey," Tobacco Control 15, 83-94.

Hymowitz, Norman, Michael K. Cummings, Andrew Hyland, William R. Lynn, Terry F. Pechacek, and Tyler D. Hartwell (1997). "Predictors of Smoking Cessation in a Cohort of Adult Smokers Followed for Five Years," Tobacco Control 6, 57-62.

Jamieson, Patrick, and Daniel Romer. (2001). "A Profile of Smokers and Smoking." In Paul Slovic (ed.), Smoking: Risk, Decision, \& Policy. Thousand Oaks, CA: Sage.

Jones, Andrew. (1999). "Adjustment Costs, Withdrawal Effects, and Cigarette Addiction," Journal of Health Economics 18, 125-137.

Liu, Jin-Tan, and Chee-Ruey Hsieh. (1995). "Risk Perception and Smoking Behavior: Empirical Evidence from Taiwan," Journal of Risk and Uncertainty 11, 139-157.

Lloyd, Barbara, and Kevin Lucas. (1998). Smoking in Adolescence: Images and Identities. London: Routledge.

Lundborg, Petter. (2006). "Having the Wrong Friends? Peer Effects in Adolescent Substance Use," Journal of Health Economics 25, 214-233.

Lundborg, Petter, and Björn Lindgren. (2002). "Risk Perceptions and Alcohol Consumption among Young People," Journal of Risk and Uncertainty 25, 165-183. 
Lundborg, Petter, and Björn Lindgren. (2004). "Do They Know What They are Doing? Risk Perceptions and Smoking Behaviour among Swedish Teenagers," Journal of Risk and Uncertainty 28, 261-286.

Nichter, Mimi, Mark Nichter, Nancy Vuckovic, Gilbert Quintero, and Cheryl Ritenbaugh. (1997). "Smoking Experimentation and Initiation among Adolescent Girls: Qualitative and Quantitative Findings," Tobacco Control 6, 285-295.

Orphanides, Athanasios, and David Zervos. (1995). "Rational Addiction with Learning and Regret," Journal of Political Economy 103, 739-758.

Pagan, Adrian R., and Anthony D. Hall. (1983). "Diagnostic Tests as Residual Analysis," Econometric Reviews 2, 159-218.

Rice, Nigel, and Matthew Sutton. (1998). "Drinking Patterns within Households: The Estimation and Interpretation of Individual and Group Variables," Health Economics 7, 689-699.

Skolverket. (2000). Nationella kvalitetsgranskningar 1999. Skolors arbete mot mobbning och annan kränkande behandling. Sex — och samlevnadsundervisningen. Undervisningen om tobak, alkohol och andra droger. Rapport nr 180. Stockholm: Liber.

Slovic, Paul. (2000). "What Does it Mean to Know a Cumulative Risk? Adolescents' Perceptions of Short-term and Long-term Consequences of Smoking," Journal of Behavioral Decision Making 13, 259-266.

SOU. (1999:137). Hälsa på Lika Villkor [Towards Public Health on Equal Terms]. Stockholm: Fritzes offentliga publikationer.

Staiger, Douglas, and James H. Stock. (1997). "Instrumental Variables Regression with Weak Instruments," Econometrica 65, 557-586.

Tobaksfakta. (2006). Tobaksfakta.se.

Tucker, Joan S., Ellickson, Phyllis L., Orlando, Maria, and Klein David J. (2005). "Predictors of Attempted Quitting and Cessation among Young Adult Smokers," Preventive Medicine 41, 554-561.

Viscusi, W. Kip. (1990). "Do Smokers Underestimate Risks?” Journal of Political Economy 98, 12531268 .

Viscusi, W. Kip. (1991). "Age Variations in Risk Perceptions and Smoking Decisions," The Review of Economics and Statistics 73, 577-588.

Viscusi, W. Kip. (1998). “Constructive Cigarette Regulation,” Duke Law Journal 47, 1095-1131.

Viscusi, W. Kip. (2002). Smoke-filled Rooms: A Postmortem on the Tobacco Deal. Chicago: University of Chicago Press.

Viscusi, W. Kip, Carvalho, Irineu, Antoñanzas, Fernando, Rovira, Joan, Braña, Francisco J., and Portillo, Fabiola (2000). "Smoking Risks in Spain: Part III-Determinants of Smoking Behaviour," Journal of Risk and Uncertainty 21, 187-212.

Weinstein, Neil D. (1999). “Accuracy of Smokers' Risk Perceptions,” Nicotine \& Tobacco Research 1, 123-130.

Weinstein, Neil D., Paul Slovic, and Ginger Gibson (2004). “Accuracy and Optimism in Smokers' Beliefs about Quitting," Nicotine \& Tobacco Research 6, 375-380.

World Bank. (1999). Curbing the Epidemic: Governments and the Economics of Tobacco Control, http:// www1.worldbank.org/tobacco/reports.htm. 